\title{
Casearia sylvestris SW. (SALICACEAE) E JACARANDA PUBERULA CHAM. (BIGNONIACEAE): USO POPULAR VERSUS LITERATURA CIENTÍFICA
}

\section{Casearia sylvestris SW.(SALICACEAE) AND JACARANDA PUBERULA CHAM.: FOLK MEDICINE VERSUS SCIENTIFIC LITERATURE.}

\author{
Darabas, A.M.'; Moreira, J.2; Rossato, A.E.; Citadini-Zanette, V..; Amaral, P.A. ${ }^{3 *}$ \\ ${ }^{1}$ Farmacêutica do Curso de Farmácia da Universidade do Extremo Sul Catarinense (UNESC). \\ ${ }^{2}$ Acadêmico do Curso de Farmácia da UNESC. \\ ${ }^{3}$ Professora do Curso de Farmácia (UNESC). \\ ${ }^{4}$ Herbário Pe. Dr. Raulino Reitz, (UNESC). \\ 1,2,3,4UNESC, Av. Universitária n'1105, Bairro: Universitário, CEP: 88806-000, Criciúma - SC, Brasil. * \\ paa@unesc.net, \\ REC: 02/09 AC:03/09
}

\begin{abstract}
RESUMO:
A utilização de plantas medicinais é notória, entretanto, nem todas possuem ações terapêuticas cientificamente comprovadas. Este artigo é resultado de um levantamento bibliográfico sobre duas árvores medicinais presentes no Parque Ecológico Municipal José Milanese (PEMJM), localizado no Bairro Mina União, no município de Criciúma, Santa Catarina e utilizadas pela população local por apresentarem efeitos terapêuticos. Trata-se de uma revisão de cunho científico sobre os efeitos terapêuticos apontados pela comunidade e posteriormente confrontados em periódicos reconhecidos pela comunidade científica. Foram estudadas Casearia sylvestris Sw.(Salicaceae) e Jacaranda puberula Cham. (Bignoniaceae) nas base de dados eletrônicas Pubmed e Science Direct, cujas informações foram fundamentais para comparar seus possíveis usos medicinais. Pode-se observar que alguns relatos populares vêm ao encontro das informações obtidas nesses bancos de dados, e outras extrapolam as informações populares.
\end{abstract}

Palavras-chave: saber popular, conhecimento científico, árvores medicinais, floresta Atlântica.ABSTRACT:

The medicinal plants are hugely used, however, few have therapeutic action scientifically confirmed. The present paper is a short review based on scientific literatures of two medicinal trees occurring at the Municipal Ecological Park José Milanese (PEMJM), located in Mina União, in the Criciúma municipality, Santa Catarina state. These are used for this community due to presence of therapeutic effects. A literary evaluation was made confronting the therapeutic effects related by the community with data available in scientific literature. Casearia sylvestris Sw. and Jacaranda puberula Cham. had been analyzed in electronic databases such as Pubmed and Science Direct, which are of fundamental importance to understand and to compare the trees and its possible medicinal uses. It was observed that some accounts matched the information obtained in databases, while others did not.

Key works: folk knowledge, science knowledge, medicinal tree, Atlantic forest.

\section{INTRODUÇÃO}

Desde épocas ancestrais, as plantas sempre estiveram ligadas ao cotidiano do homem, servindo-lhe de alimento e remédio aos seus males (Bendazzoli, 2000). Com o passar do tempo as populações foram se adaptando ao meio, dividindo-se em várias culturas e classes sociais, as quais foram adquirindo conhecimento sobre plantas, que 
ficaram em suas raízes com os conceitos de saúde e de doença (Duniau, 2003).

O emprego de plantas medicinais na recuperação da saúde tem evoluído ao longo dos tempos, desde as formas mais simples de tratamento local, provavelmente utilizada pelo homem das cavernas até as formas tecnologicamente sofisticadas da fabricação industrial utilizada pelo homem moderno (Lorenzi \& Matos, 2008).

Grande parte do conhecimento sobre as plantas medicinais foi passada oralmente ao longo de gerações, que juntamente com mitos e rituais, formaram parte importante das culturas locais (Lorenzi \& Matos, 2008). A arte de benzedores, curandeiros e xamãs, herdada dos magos e feiticeiros de outrora, pode ser vista hoje, em teste, nos laboratórios científicos, os quais passaram a avaliar experimentalmente a veracidade destas informações, tendo em vista a descoberta de novos medicamentos (Di Stasi, 1996).

Muitas plantas medicinais utilizadas em rituais religiosos possuem estudos científicos que comprovam as propriedades farmacológicas e dão sentido as utilizações ritualísticas (Farelli, 2002).

As plantas medicinais desempenham papel muito importante no mundo da saúde. Mesmo com grandes avanços observados na medicina moderna, nas ultimas décadas, as plantas contribuem de forma significativa no cuidado da saúde da população (Calixto, 2000).

Usuários de plantas medicinais de todo o mundo mantêm a prática do consumo de plantas medicinais, sendo muito importantes as informações terapêuticas que foram acumuladas durante séculos. De modo indireto, este tipo de cultura medicinal desperta o interesse de pesquisadores em estudos envolvendo áreas multidisciplinares, como por exemplo, botânica, farmacologia e fitoquímica, que juntas enriquecem os conhecimentos sobre a abundante fonte medicinal natural: a flora mundial (Maciel et al.,2002).

Neste contexto é relevante lembrar que as plantas, além de seu uso na medicina popular com finalidades terapêuticas, têm ao longo dos anos, contribuído para a obtenção de vários fármacos (Farnsworth, 1980).

Barreiro (2001) ressalta que diferentes classes químicas de produtos naturais originaram diversos fármacos, de distintas categorias terapêuticas, como por exemplo, a mesembrina, um alcalóide indolinônico isolado de Sceletium expansum (Aizoaceae), é o principal componente químico de uma poção mágica empregada por tribos africanas e foi recentemente patenteado para emprego como antidepressivo. A papaverina, um alcalóide isoquinolínico que foi largamente empregado como vasodilatador cerebral contribuiu para o conhecimento da fisiopatologia da disfunção eréctil que resultou na recente descoberta do sildenafil (Viagra®).

A partir dessas informações constata-se que dos medicamentos produzidos pela indústria e comercializados nas farmácias e drogarias, $25 \%$ tem componentes químicos de plantas. No caso de medicamentos homeopáticos, esta porcentagem aumenta para 60\% (Corrêa, 1998).

A falta de informações adequadas sobre as propriedades das plantas medicinais, seu consumo concomitante com os medicamentos tradicionais (alopáticos) sem aviso ao médico e, finalmente, a perda do conhecimento sobre os efeitos medicinais e tóxicos das plantas, assim como a capacidade de identificá-las pela migração da população 
rural para as cidades, são fatores preocupantes da automedicação e da utilização irracional das plantas medicinais (Albuquerque \& Hanazaki, 2006; Veiga Jr. et al., 2005).

Com a grande expansão do uso de plantas medicinais, foram pesquisados novos conhecimentos sobre as plantas e suas propriedades terapêuticas. Com isso, profissionais da área da saúde e órgãos governamentais passaram a requerê-las como possível alternativa terapêutica no atendimento de algumas necessidades de saúde (Simões, 1998).

As novas tendências globais de uma preocupação com a biodiversidade e as idéias de desenvolvimento sustentável trouxeram novas áreas ao estudo de plantas medicinais brasileiras, que acabaram despertando um interesse voltado para a fitoterapia. Novas linhas de pesquisa foram estabelecidas em Universidades brasileiras, algumas delas buscando bases mais sólidas para a validação científica do uso de plantas medicinais (Lorenzi \& Matos, 2008).

Segundo Vanaclocha (2003) fitoterapia é a ciência que estuda a utilização dos produtos de origem vegetal com a finalidade terapêutica de prevenir, amenizar e curar um estado patológico.

Conforme a legislação em vigor no país entende-se como fitoterápico "medicamento obtido empregando-se exclusivamente matérias-primas vegetais. É caracterizado pelo conhecimento da eficácia e dos riscos do seu uso, assim como pela reprodutibilidade e constância de sua qualidade. Sua eficácia e segurança são validadas por meio de levantamentos etnofarmacológicos de utilização, documentações tecnocientíficas em publicações ou ensaios clínicos fase 3". Não se considera medicamento fitoterápico aquele que em sua composição, inclua substâncias ativas isoladas, de qualquer origem, nem as associações destes como extratos vegetais (Brasil, 2004).

Nos últimos anos, tem-se verificado um grande avanço científico envolvendo os estudos químicos e farmacológicos de plantas medicinais, os quais visam obter novos compostos com propriedades terapêuticas. Isto pode ser claramente observado pelo aumento de trabalhos publicados nesta área, tanto em congressos como em periódicos nacionais e internacionais (Yunes \& Cechinel-Filho, 1998).

Algumas questões misturam o conhecimento popular ao científico e são respondidas através das comprovações científicas e da ampliação dos estudos das plantas brasileiras, principalmente nas áreas de fitoquímica e etnofarmacologia (Maciel et al., 2002).

Portanto, o presente trabalho teve como objetivo confrontar as informações de cunho popular com o científico, sobre duas árvores medicinais presentes no Parque Ecológico Municipal José Milanese, em Criciúma, Santa Catarina.

\section{MATERIAL E MÉTODOS}

O Parque Ecológico Municipal José Milanese (PEMJM), localiza-se no Bairro Mina União, município de Criciúma, Santa Catarina (2848'S e 4925'W, altitude média de $34 \mathrm{~m}$ ) e serviu de fonte de informação para a realização do presente estudo. A vegetação faz parte da Floresta Ombrófila Densa Submontana e passou por corte seletivo nos anos 80 , porém ainda apresenta características de floresta primária 
(Figueiró-Leandro \& Citadini-Zanette, 2008).

As árvores medicinais do PEMJM foram relacionadas por Figueiró-Leandro \& Citadini-Zanette (2008), com base em pesquisa etnobotânica realizada na literatura popular e em Tomazi \& Rossato (2008) que entrevistaram a comunidade que reside no entorno do referido Parque. Destas plantas, foram selecionadas Casearia sylvestris Sw. e Jacaranda puberula Cham., por apresentarem relevante indicação terapêutica pela comunidade do PEMJM e possuirem ampla distribuição geográfica.

Os artigos selecionados para este levantamento foram somente os relacionados à atividade biológica apresentada por ambas espécies.

C. sylvestris. e J. puberula foram confrontadas cientificamente com o uso popular por meio de busca em duas base de dados eletrônicas (Pubmed e Science Direct), consultando-se publicações dos últimos dez anos (1998-2008). Por J. puberula apresentar pequena expressão bibliográfica no período determinado, sua busca foi ampliada para 1968-2008.

As plantas encontram-se depositadas no Herbário Pe. Dr. Raulino Reitz da Universidade do Extremo Sul Catarinense com registro CRI 7595 (C. sylvestris) e CRI 7381 (J. puberula).

\section{RESULTADOS E DISCUSSÃO}

\subsection{Casearia sylvestris Sw. (Figura 1)}

Casearia sylvestris, pertencente à família Salicaceae, é uma árvore que geralmente apresenta de 4-6 metros de altura, mas pode atingir até 20 metros; apresenta copa densa e arredondada, com tronco de 20-30 cm de diâmetro; suas folhas são persistentes, assimétricas na base e com bordos serrilhados, de 6-12 cm de comprimento; as flores são pequenas, esbranquiçadas, reunidas em glomérulos axilares (Lorenzi, 1992; Carvalho, 2006); os frutos são cápsulas ovóides, vermelhos, com cerca de $5 \mathrm{~mm}$ de diâmetro e com cálice persistente, com 1 a sete sementes (Carvalho, 2006). 


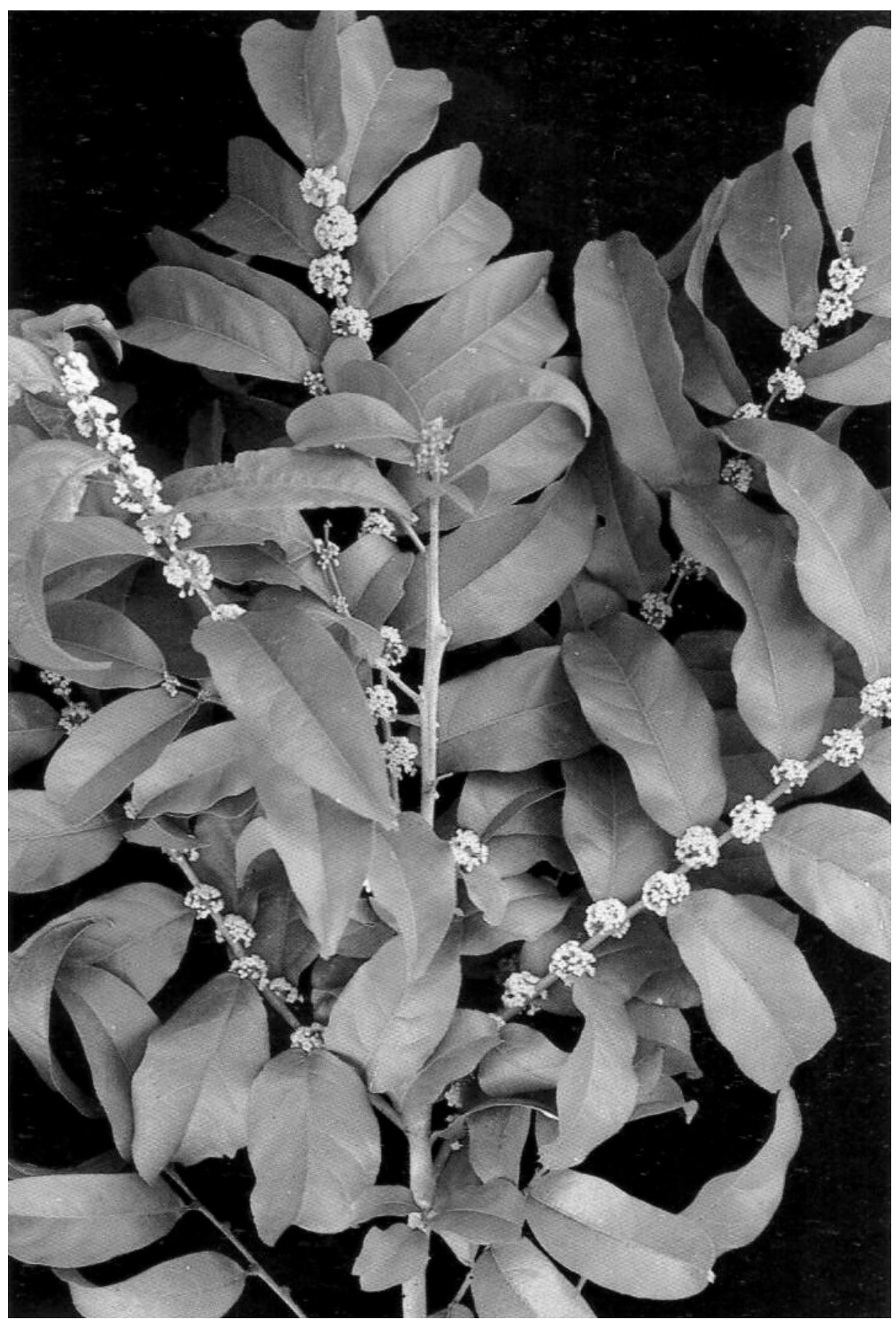

FIGURA 1 - DETALHE DE UM RAMO COM FLORES E INFLORESCÊNCIA. FONTE: LORENZI (1992).

É popularmente conhecida como "guaçatonga", um termo originado do idioma tupi-guarani, indicando um antigo uso dessa espécie em comunidades indígenas 
brasileiras (Carvalho, 2006). E como tal, também é denominada pela comunidade estudada como guaçatonga (Tomazi; Rossato, 2008).

É ainda conhecida como apiá-acanoço, bugre-branco, café-bravo, café-de-frade, cafezinho-do-mato, cafezeiro-do-mato, cambroé, chá-de-bugre, erva-de-bugre, ervalagarto, erva-pontada, fruta-de-saíra, guaçatunga, guaçatunga-preta, língua-de-teju, língua-de-tiú, pau-de-lagarto, petumba (Lorenzi \& Matos, 2008).

C. sylvestris está distribuída em todo território brasileiro (Hoehne, 1939), com prevalência destacada no sul e sudeste do Brasil (Lorenzi \& Matos, 2008). Floresce nos meses de junho a agosto e seus frutos amadurecem a partir de setembro, prolongando-se até meados de novembro (Lorenzi, 1992). Por ocupar diferentes ambientes, essa espécie proporciona grande variação com relação ao tamanho, à forma e textura das folhas, e à pilosidade dos ramos mais jovens (Torres \& Yamamoto, 1986).

C. sylvestris é uma planta utilizada na medicina popular no Brasil para tratar vários tipos de doenças, mais notadamente para curar feridas dérmicas e úlceras gástricas, para promover a anestesia local e como antisséptico (Alonso, 2004). O uso popular da guaçatonga na região carbonífera sul-catarinense, relatado por Tomazi \& Rossato (2008) por informações obtidas das agentes da Pastoral da Saúde residentes no bairro Mina União e comunidade local, são apresentadas no quadro 1.

QUADRO 1 - USO POPULAR DA ÁRVORE MEDICINAL CASEARIA SYLVESTRIS SW. DE ACORDO COM TOMAZI \& ROSSATO (2008).

\begin{tabular}{ccccc}
\hline \multirow{2}{*}{ Nome científico } & $\begin{array}{c}\text { Indicação } \\
\text { terapêutica }\end{array}$ & Parte utilizada & $\begin{array}{c}\text { Técnica de } \\
\text { preparo }\end{array}$ & $\begin{array}{c}\text { Solvente } \\
\text { utilizado }\end{array}$ \\
\hline & Colesterol & Folhas & Infusão & Água \\
\cline { 2 - 4 } & Circulação & Folhas & Decocção & Água \\
\cline { 2 - 4 } Casearia & Coração & Folhas & Infusão & Água \\
\cline { 2 - 4 } sylvestris Sw. & Pressão alta & Folhas & Infusão & Água \\
\cline { 2 - 5 } & Diabetes & Folhas & Infusão & Água \\
\cline { 2 - 4 } & Emagrecer & Folhas & Infusão & Água \\
\cline { 2 - 4 } & Diurético & Folhas & Decocção & Água \\
\cline { 2 - 4 } & & Folhas & Xarope & $\begin{array}{c}\text { Água e açúcar } \\
\text { mascavo }\end{array}$ \\
\cline { 2 - 4 } & & Folhas & Decocção & Água \\
\cline { 2 - 4 } & Perna inchada & Folhas & Xarope & $\begin{array}{c}\text { Água e açúcar } \\
\text { mascavo }\end{array}$ \\
\cline { 2 - 4 } & & Folhas & Lavagem externa & Água \\
\hline
\end{tabular}

Observa-se que são utilizadas as folhas como farmacógeno, o método de preparo varia entre infusão, decocção, tintura e xarope e as indicações terapêuticas levantadas pela comunidade são principalmente para o sistema circulatório, colesterol e diabetes.

As informações de cunho científico que fundamentam os dados levantados de uso popular são apresentadas no Quadro 2. 


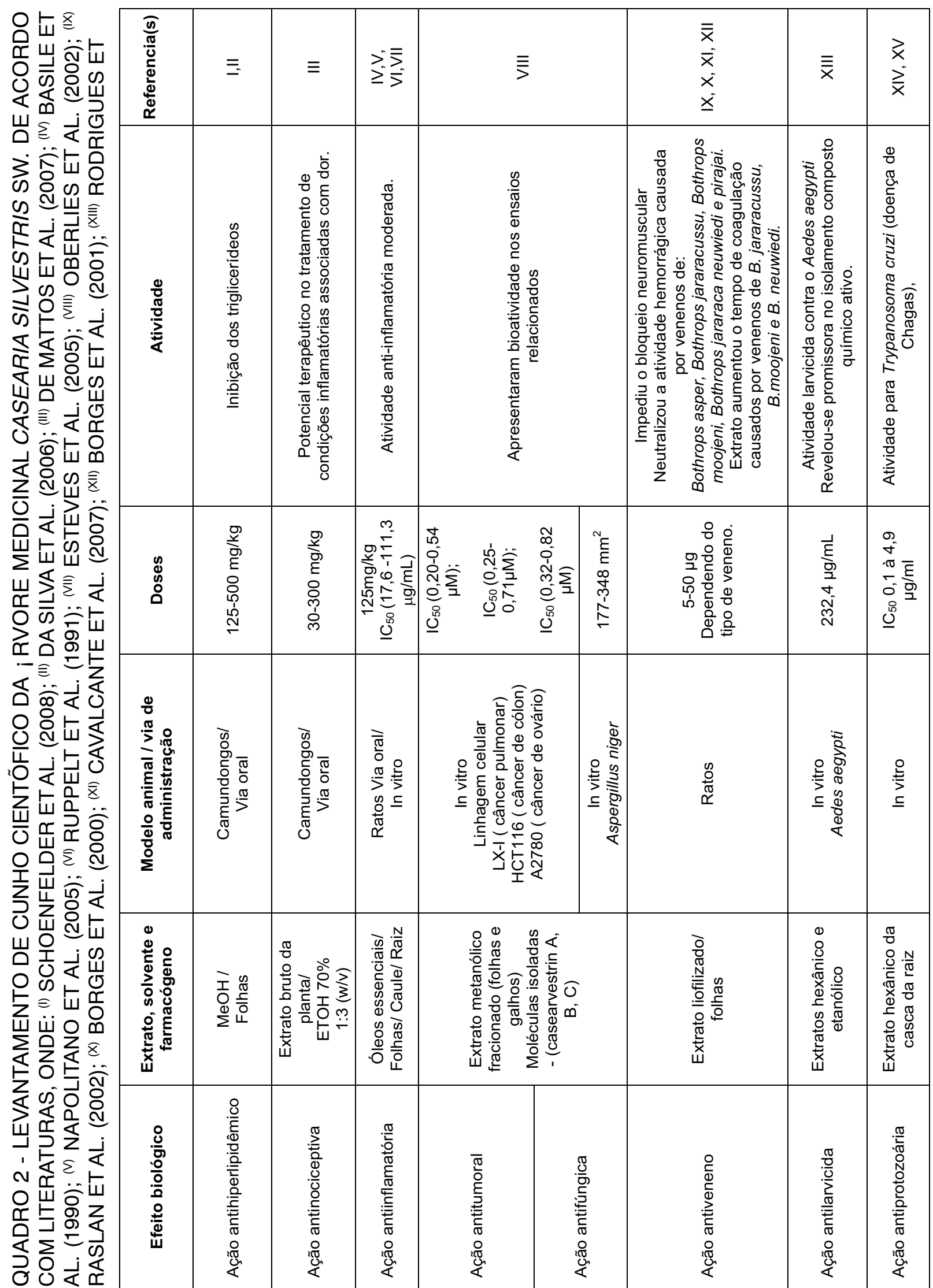


De acordo com Schoenfelder et al. (2008), C. sylvestris demonstrou atividades antihiperlipidêmicas, empregando-se o extrato metanólico $(\mathrm{MeOH})$ das folhas em testes com camundongos nas doses de 150 a $500 \mathrm{mg} / \mathrm{kg}$, via oral, com resultados que indicaram a inibição dos triglicerídeos.

O extrato bruto da planta em álcool etanólico $(\mathrm{ETOH})$ foi testado para avaliação da ação antinociceptiva em camundongos, por via oral, em doses de $30-300 \mathrm{mg} / \mathrm{kg}$, os resultados obtidos demonstraram inibição da dor ligada a processos inflamatórios (Mattos et al., 2007).

O óleo essencial extraído a partir das folhas de $C$. sylvestris foi testado em ratos, por via oral e intraperitonial, para avaliação da ação antiinflamatória. Resultados promissores foram observados na atenuação de processos inflamatórios em testes como o de permeabilidade vascular, edema de pata, teste de tecido granulomatoso, e modelo do ácido acético (Esteves et al., 2005; Napolitano et al., 2005; Ruppelt et al., 1991; Basile et al., 1990,).

Para avaliar as atividades antitumoral e antifúngicas testes in vitro foram executados, de moléculas isoladas a partir de C. sylvestris, casearvestrin A, B, C. Essas moléculas foram testadas sob as linhagens celulares LX-I (câncer pulmonar) HCT116 (câncer de cólon) A2780 (câncer de ovário) e observou-se uma inibição do crescimento celular relativamente significativa, provocada pela casearvestrin $B(0,20$ $\mu \mathrm{M})$ em relação ao padrão camptotecine $(0,12 \mu \mathrm{M})$. Para ação antifúngica foi observado inibição contra o Aspergillus niger na ordem $0,34 \mu \mathrm{g} / \mathrm{mL}$ para casearvestrin $\mathrm{C}$ contra 0 padrão camptotecine $(0,01 \mu \mathrm{g} / \mathrm{mL})$ (Oberlies et al., 2002)

Para ação antiveneno o extrato liofilizado das folhas de $C$. sylvestris foi testado em ratos em doses de 5-50 $\mu \mathrm{g}$ dependendo do tipo de veneno. Observou-se bloqueio neuromuscular, neutralizando a atividade hemorrágica causadas por venenos de: Bothrops asper, Bothrops jararacussu, Bothrops moojeni, Bothrops jararaca neuwiedi e pirajai. O extrato foi capaz de inibir, em modelo animal, a atividade anticoagulante provocada por fosfolipases específicas presentes nos venenos de $B$. jararacussu, $B$. moojeni e B. neuwiedi (Raslan et al., 2002; Borges et al., 2000; Cavalcante et al., 2007; Borges et al., 2001). Para ação antilarvativa foi realizado o extrato hexânico e etanólico, sendo testados in vitro, em doses de $500 \mathrm{ig} / \mathrm{mL}$, apresentando atividade larvativa contra Aedes aegypti (Rodrigues et al., 2006).

Para ação antiprotozoária foi analisado o extrato hexânico da casca da raiz, sendo testado in vitro, em doses de 0,1 a $4,9 \mathrm{ig} / \mathrm{mL}$, apresentando atividade contra Trypanosoma cruzi (doença de Chagas) (Mesquita et al.,2005; Espindola et al., 2004).

\subsection{Jacaranda puberula Cham. (Figura 2)}

Jacaranda puberula, pertencente à família Bignoniaceae, é uma árvore caducifólia, de pequeno porte, de 2 a 8 metros altura; apresenta caule com fuste longo, de até $40 \mathrm{~cm}$ de diâmetro com casca acinzentada, áspera e fissurada longitudinalmente; folhas opostas, compostas, bipinadas, de até $6 \mathrm{~cm}$ comprimento, com 4 a 7 pares de pinas e com até 10 pares de foliólulos rômbico-elípticos; inflorescência tirso terminal; flores tubulosas, pentâmeras, hermafroditas, de até $7 \mathrm{~cm}$ de comprimento; fruto do tipo cápsula, elíptico-oblongo, lenhoso, de até $8,5 \mathrm{~cm}$ de comprimento e até $5,5 \mathrm{~cm}$ de 
largura; sementes aladas, hialinas, circulares, de até $2,3 \mathrm{~cm}$ de largura (Backes \& Irgang, 2004).

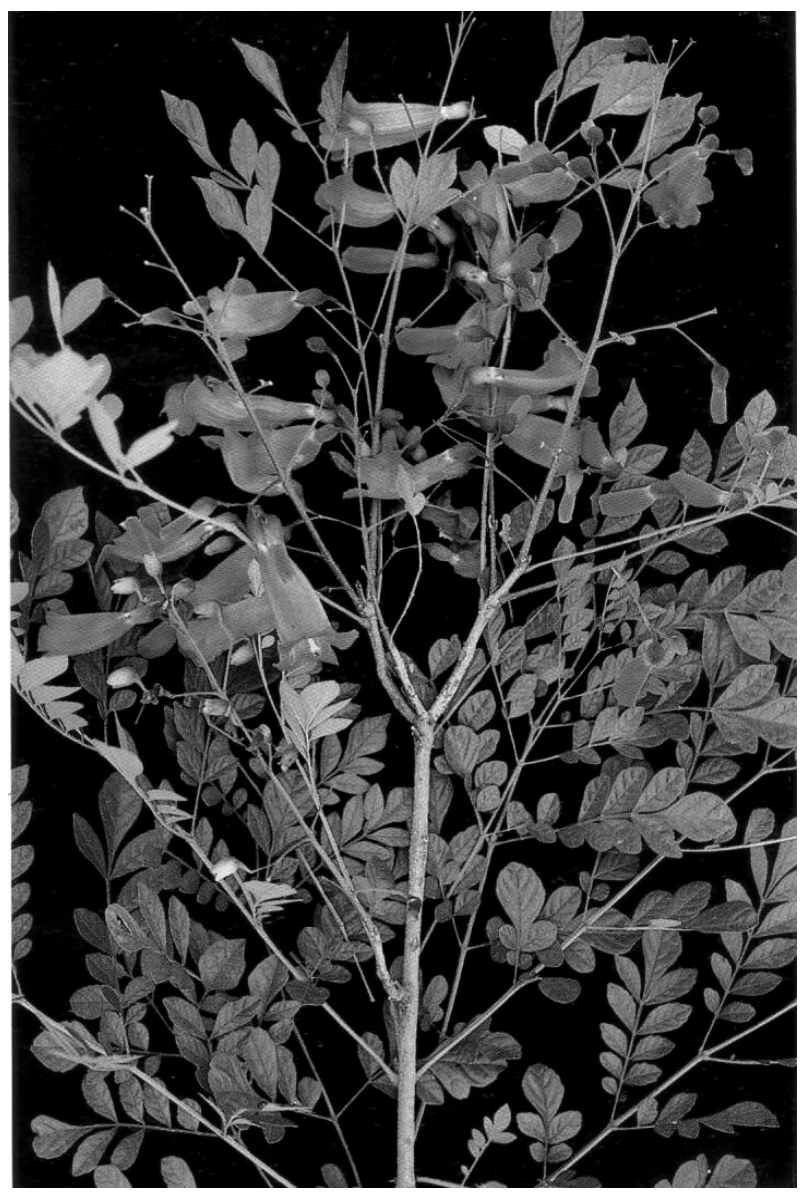

FIGURA 2 - DETALHE DE UM RAMO COM FLORES E INFLORESCÊNCIA. FONTE:LORENZI (1992).

J. puberula é conhecida principalmente como caroba ou carobinha, mas também é denominada popularmente como carobeira, caroba-rocha, caroba-do-campo, carobamuída, caroba-pequena (Sandwith; Hunt, 1974)

Floresce de setembro a dezembro, podendo se estender até fevereiro (Sandwith; Hunt, 1974).

É uma planta heliófita e seletiva higrófita, comumente encontrada em capoeiras e capoeirões situados em solos úmidos de planícies, aclives suaves e solos pedregosos, apresentando grande afinidade com a vegetação secundária, sobretudo na mata pluvial de encosta atlântica (Sandwith; Hunt, 1974; Inoue, 1984). É muito comum encontrá-la do Rio de Janeiro ao Rio Grande do Sul, na Mata Atlântica (Backes; Irgang, 2004).

As informações populares de J. puberula, obtidas na comunidade do bairro Mina União, segundo Tomazi e Rossato (2008), encontram-se na Tabela 3. 
QUADRO 3 - USO POPULAR DA ARVORE MEDICINAL JACARANDA PUBERULA CHAM. DE ACORDO COM TOMAZI \& ROSSATO (2008).

\begin{tabular}{ccccc} 
Nome científico & $\begin{array}{c}\text { Indicação } \\
\text { terapêutica }\end{array}$ & Parte utilizada & $\begin{array}{c}\text { Técnica de } \\
\text { preparo }\end{array}$ & Solvente utilizado \\
\hline \multirow{2}{*}{$\begin{array}{c}\text { Alergias, frieira, } \\
\text { inflamação, } \\
\text { "doenças-de- } \\
\text { pele", sarna, } \\
\text { cobreiro }\end{array}$} & Folhas & Lavagem externa & Água \\
\cline { 2 - 5 } & $\begin{array}{c}\text { Tosse, bronquite } \\
\text { alérgica }\end{array}$ & Folhas & Xarope & $\begin{array}{c}\text { Água + açúcar } \\
\text { mascavo + laranja } \\
\text { inteira + cachaça }\end{array}$ \\
\cline { 2 - 5 } & $\begin{array}{c}\text { Intoxicação do } \\
\text { veneno de roça }\end{array}$ & Folhas & Infusão & Água \\
\hline
\end{tabular}

Como se observa no quadro 3 , as folhas são utilizadas como farmacógeno, 0 método de preparo varia entre xarope, lavagem externa e infusão, e as indicações terapêuticas levantadas pela comunidade são para problemas no sistema respiratório e problemas na pele como frieiras, inflamação, cobreiro e sarna.

Embora realizada busca intensiva nas bases de dados eletrônicas consultadas, J. puberula, no âmbito de sua atividade biológica, foi encontrada em apenas dois trabalhos (Tabela 4).

QUADRO 4 - LEVANTAMENTO DE CUNHO CIENTÍFICO DA ÁRVORE MEDICINAL JACARANDA PUBERULA DE ACORDO COM LITERATURAS, ONDE (I) PASSERO

\begin{tabular}{cccccc}
\hline $\begin{array}{c}\text { Efeito } \\
\text { biológico }\end{array}$ & $\begin{array}{c}\text { Extrato,solvente } \\
\text { e farmacógeno }\end{array}$ & $\begin{array}{c}\text { Modelo animal/ } \\
\text { via de } \\
\text { administração }\end{array}$ & Doses & Atividade & Referências \\
\hline $\begin{array}{c}\text { Ação } \\
\text { antiprotozoária }\end{array}$ & $\begin{array}{c}\text { Extrato } \\
\text { metanólico/ } \\
\text { Folhas }\end{array}$ & In vitro & $\mathrm{IC}_{50}(88,0$ & $\begin{array}{c}\text { Mostrou atividade } \\
\text { contra Leishmania } \\
\text { (Leishmania) } \\
\text { amazonensis. }\end{array}$ & I \\
\hline $\begin{array}{c}\text { Ação } \\
\text { antibacteriana }\end{array}$ & $\begin{array}{c}\text { Extrato etanólico } \\
\text { bruto das folhas }\end{array}$ & In vitro & $500 \mu \mathrm{g} / \mathrm{ml})$ & $\begin{array}{c}\text { Apresentou atividade } \\
\text { antibacteriana em parte } \\
\text { de seus extratos o que } \\
\text { pode justificar seu uso } \\
\text { medicinal em feridas } \\
\text { infectadas }\end{array}$ & II \\
\hline
\end{tabular}

Embora os integrantes da Pastoral da Saúde do Bairro Mina União e comunidade local relatassem o uso em feridas, inflamações, entre outros (veja quadro 3), foi encontrado um único estudo realizado por Kuster et al. (2006) que descreve ação antibacteriana para o extrato $n$-hexano e diclorometado de J. puberula em concentração de $500 \mu \mathrm{g} / \mathrm{mL}$. Porém, poucas informações foram obtidas por tratar-se de um trabalho em forma de resumo apresentado na 29a Reunião Anual da Sociedade Brasileira de Química (SBQ).

De acordo com Passero et al (2007), J.puberula pode ser utilizada como antiprotozoária, sendo o extrato metanólico testado para leishmania, observou uma 
atividade antimastigota na concentração $I_{50}$ de $88,0 \mu \mathrm{g} / \mathrm{mL}$. Neste mesmo estudo detectou também ação citotóxica macrofágica na concentração $I_{50}$ de $14,0 \mu \mathrm{g} / \mathrm{mL}$.

Algumas das indicações terapêuticas relatadas pelo uso popular por Tomazzi e Rossato (2008), não foram encontradas nos artigos científicos revisados, provavelmente porque ainda não foram estudadas ou ainda não houve interesse por parte da comunidade científica.

\section{CONCLUSÃO}

Para C. sylvestris, foram encontrados dois estudos que relataram ação antihiperlipidêmica, que ratificam as indicações terapêuticas populares para coração e colesterol, relatadas pela comunidade do bairro Mina União.

Contudo para J.puberula foi encontrado apenas um único estudo (como resumo apresentado em Congresso) que relata ação antibacteriana, corroborando com a indicação terapêutica popular para inflamação e feridas dérmicas, relatadas pela comunidade local.

Como constatado pela pesquisa realizada, as plantas estudadas apresentam efeitos medicinais relevantes relatados no uso popular, o que poderá incentivar pesquisadores a se inclinarem ainda mais para a investigação científica destes possíveis efeitos terapêuticos.

O saber popular, por meio da etnobotânica, é de fundamental importância, uma vez que pode nortear pesquisadores na busca de moléculas bioativas que possam ser candidatas a fármacos.

\section{REFERÊNCIAS}

ALBUQUERQUE, U.P.; HANAZAKI, N. As pesquisas etnodirigidas na descoberta de novos fármacos de interesse médico e farmacêutico: fragilidades e perspectivas. Revista Brasileira de Farmacognosia. v.16, p.678-89, 2006.

ALONSO, J. Tratado de Fitofármacos y Nutracêuticos. Corpus Libros, Rosario, Argentina, 2004, 953 p.

BACKES, P.; IRGANG, B. Mata Atlântica: as árvores e a paisagem. Porto Alegre: Paisagem do Sul, 2004. 393p.

BARREIRO, E.J.; FRAGA, C.A.M. Química medicinal: as bases moleculares da ação dos fármacos. Porto Alegre: Artmed, 2001. 243 p.

BASILE, A.C. et al. Pharmacological assay of Casearia sylvestris. I: Preventive antiulcer activity and toxicity of the leaf crude extract. Journal of Ethnopharmacology. v.30, n.2, p.185-197, 1990.

BENDAZZOLI, W.S. Fitomedicamentos: perspectivas de resgate de uma terapia histórica. Mundo saúde, São Paulo, v.24, n.2, p.123-126, 2000. 
BORGES, M.H. et al. Effects of aqueous extract of Casearia sylvestris (Flacourtiaceae) on actions of snake and bee venoms and on activity of phospholipases A2. Comparative Biochemistry and Physiology - Part B Biochemistry and Molecular Biology. v.127, n.1, p.21-30, 2000.

BORGES, M.H. et al. Neutralization of proteases from Bothrops snake venoms by the aqueous extract from Casearia sylvestris (Flacourtiaceae). Toxicon. v.39, n.12, p.1863$9,2001$.

BRASIL. Ministério da saúde. ANVISA (Agencia Nacional de Vigilância Sanitária). Resolução RDC (Resolução de Diretoria Colegiada) ํo 48, de 16 de março de 2004. Disponível em: http://elegis.anvisa.gov.br/leisref/public/showAct.php?id=10230\& \&word=. Acesso em: 14 set. 2008.

CALIXTO, J.B. Efficacy, safety, quality control, marketing and regulatory guidelines for herbal medicines (phytotherapeutic agents). Brazilian Journal of Medical and Biological Research, v.33, n.2. p.179-89, 2000.

CARVALHO, P.E.R. Espécies arbóreas brasileiras. Brasília: EMBRAPA, v.2, 2006. 627p.

CAVALCANTE, W.L. et al. Neutralization of snake venom phospholipase A2 toxins by aqueous extract of Casearia sylvestris (Flacourtiaceae) in mouse neuromuscular preparation. Journal of Ethnopharmacology. v.112, n.3, p. 490-7, 2007.

CORRÊA, A.D.; BATISTA, R.S.; QUINTAS, L.E.M. Plantas medicinais: do cultivo a terapêutica. 5 ed. Petrópolis : Vozes, 2002. 247p.

DA SILVA, A.C. et al. Inhibition of NTPDase, 5'-nucleotidase, Na+/K+-ATPase and acetylcholinesterase activities by subchronic treatment with Casearia sylvestris. Phytomedicine. v.13, n.7, p.509-14, 2006.

DISTASI, L. C. Plantas medicinais: arte e ciência, um guia de estudo interdisciplinar. São Paulo: Editora da Universidade Estadual Paulista, 1996. 230 p

DUNIAU, M.C.M. Plantas medicinais: da magia a ciência. Rio de janeiro: Brasport, 2003. $176 \mathrm{p}$.

ESPINDOLA, L.S. et al. Trypanocidal activity of a new diterpene from Casearia sylvestris var. lingua. Planta Medica, v.70, n.11, p.1093-5, 2004.

ESTEVES, I. et al. Gastric antiulcer and anti-inflammatory activities of the essential oil from Casearia sylvestris Sw. Journal of Ethnopharmacology. v.101, n.1-3, p.191-6, 2005. 
FARELLI, M.H. Plantas que curam e cortam feitiços. 6.ed. Rio de Janeiro: Pallas, 2002. 80 p.

FARNSWORTH, N. R. The development of pharmacological and chemical research for application to traditional medicine in developing countries. Journal of Ethnopharmacology. v.2, n.2, p.173-81, 1980.

FIGUEIRÓ-LEANDRO, A.C.B.; CITADINI-ZANETTE, V. Árvores medicinais de um fragmento florestal urbano no município de Criciúma, Santa Catarina, Brasil. Revista Brasileira de Plantas Medicinais, v.10, n.2, p.56-67, 2008.

HOEHNE, F.C. Plantas e substâncias vegetais tóxicas e medicinais. São Paulo, Brasil: Graphicars; 1939. 355 p.

INOUE, M.T.; RODERJAN, C.V.; KUNIYOSHI, Y.S. Projeto madeira do Paraná. Curitiba: FUPEF, 1984. 260 p.

KUSTER, M.R. Química é energia: transforma a vida e preserva o ambiente. In: 29a REUNIÃO ANUAL DA SOCIEDADE BRASILEIRA DE QUÍMICA, 29, 2006, Águas de Lindóia. Avaliação do potencial antibacteriano dos extratos de Jacaranda puberula Cham. - um estudo baseado na indicação etnofarmacológica. São Paulo, 2006.

LORENZI, H.; MATOS, F.J.A. Plantas medicinais no Brasil: nativas e exóticas. São Paulo : Instituto Plantarum, 2008. 544 p.

LORENZI, H. Árvores brasileiras: manual de identificação e cultivo de plantas arbóreas do Brasil. Nova Odessa: Plantarum, 1998. v.2, 352p.

LORENZI, H. Árvores Brasileiras: manual de identificação e cultivo de plantas arbóreas do Brasil. Nova Odessa: Plantarun, 1992. v.1, 384 p.

MACIEL, M.A.M. et al. Plantas Medicinais: a necessidade de estudos multidisciplinares. Química Nova, v.25, n.3, p.429-38, 2002.

MATTOS, E.S. et al. Evaluation of antinociceptive activity of Casearia sylvestris and possible mechanism of action. Journal of Ethnopharmacology. v.112, n.1, p. 1-6, 2007.

MESQUITA, M.L. et al. Antileishmanial and trypanocidal activity of Brazilian Cerrado plants. Memórias do Instituto Oswaldo Cruz. v.100, n.7, p.783-7, 2005.

NAPOLITANO, D.R. et al. Down-modulation of nitric oxide production in murine macrophages treated with crude plant extracts from the Brazilian Cerrado. Journal of Ethnopharmacology. v.99, n.1, p.37-41, 2005. 
OBERLIES, N.H. et al. Novel bioactive clerodane diterpenoids from the leaves and twigs of Casearia sylvestris. Journal of Natural Products. v.65, n.2, p.95-99, 2002.

PASSERO, L.F. et al. Anti-leishmania activity of semi-purified fraction of Jacaranda puberula leaves. Parasitology Research. v.101, n.3, p.677-80, 2007.

RASLAN, D.S. et al. Anti-PLA2 action test of Casearia sylvestris Sw. Bollettino Chimico Farmaceutico. v.141, n.6, p.457-60, 2002.

RODRIGUES. A.M. et al. Larvicidal activity of some Cerrado plant extracts against Aedes aegypti. Journal of the American Mosquito Control Association. v.22, n.2, p.314-7, 2006.

RUPPELT, BM. et al. Pharmacological screening of plants recommended by folk medicine as anti-snake venom-l. Analgesic and anti-inflammatory activities. Instituto Oswaldo Cruz. V.86, n.2, p.203-205, 1991.

SANDWITH, N.Y; HUNT, D.R. Herbário Barbosa Rodrigues. Bignoniáceas. Itajaí: Herbário Barbosa Rodrigues, 1974.172 p.

SCHOENFELDER, T. et al. Antihyperlipidemic effect of Casearia sy/vestris methanolic extract. Fitoterapia, v.79, n.6, p. 465-7, 2008.

SIMÕES, C.M.O. Plantas da medicina popular no Rio Grande do Sul. 5.ed. Porto Alegre: UFGRS, 1998. $172 \mathrm{p}$.

TOMAZI, L.B.; ROSSATO, A.E. Estudo etnobotânico das árvores medicinais do Parque Ecológico Municipal José Milanese. 2008. 29p. Trabalho de Conclusão de Curso. Departamento de Farmácia, Universidade do Extremo Sul Catarinense, Criciúma.

TORRES, R.B. \& YAMAMOTO, K. Taxonomia das espécies de Casearia Jacq. (Flacourtiaceae) do estado de São Paulo. Revista brasileira de botânica, v.9, n. 2, p 239-258, 1986.

VANACLOCHA, B. V.; FOLCARÀ, S. C. Fitoterapia: vademécum de prescripción. 4. ed. Barcelona: Masson, 2003. 1091 p.

VEIGA Jr. VF; MACIEL M.A.M.; PINTO, A.C. Plantas medicinais: cura segura? Química Nova, v.28, n.3, p.519-28, 2005.

YUNES, A.R. \& CECHINEL, V. Estratégias para a obtenção de compostos farmacologicamente ativos a partir de plantas medicinais. Conceitos sobre modificação estrutural para otimização da atividade. Química Nova, v.21, n.1, p.99-105, 1998. 